\title{
Short-term retention of digits: A function of item distribution with respect to time'
}

\author{
M. S. MAYZNER, M. E. TRESSELT, S. ADLER, A. COHEN AND K. M. SCHOENBERG
}

NEW YORK UNIVERSITY

In the present study 20 single digits were presented sequentially during a $40 \mathrm{sec}$. display period and five conditions of input timing distributions were examined, employing a computer-based CRT display system. In one condition the 20 digits were distributed evenly through time at a rate of 2 sec. per digit. In the other four conditions the 20 digits were presented at a rate of $1 \mathrm{sec}$. per digit and the remaining 20 sec. was distributed in various ways throughout the total $40 \mathrm{sec}$. display period. The results showed very sianificant effects as a function of varying the input timing distributions and plots of the serial position curves revealed a highly systematic multi-bowing effect which strongly suggests that input "chunking" is time-locked to input timing distributions.

The present study is concerned with the following question: "Given a fixed number of discrete items (e.g., 20 single digits) and a fixed quantity of time (e.g., 40 sec.), how should these items be distributed through time in order to obtain maximum retention?" Traditionally, in studying the retention of a series of discrete items, such as strings of digits or letters in the typical "immediate memory span" type of experiment, the items are distributed evenly over the time period employed. However, recent studies (Mayzner \& Adler, 1965; Mayzner \& Gabriel, 1963; Miller, 1956) strongly suggest that input "chunking" is a critical variable which significantly affects the amount of information that is stored and subsequently retrieved. Therefore, it is quite probable that distributing the input in different ways through time will result in different storage capabilities, to the extent that input "chunking" is affected by such timing distributions. The present study then will vary the way 20 single digits are distributed throughout a $40-\mathrm{sec}$. time period and should provide a first assessment of the extent to which input timing distributions affect the short-term storage and retrieval of a string of discrete items.

Method

The Ss were 25 students from the Department of Industrial Engineering and Operations Research of New York University and had participated in no previous study of short-term retention.

The apparatus used to generate the stimulus strings consisted of a PDP-7 on-line high-speed digital computer coupled to two CRT display consoles (a Master Display, Type 340 and a Slave Display, Type 343; computer and both displays manufactured by the Digital Equipment Corp., Maynard, Mass.). A computer program was written which generated for display 50 different strings of 20 random digits each, with the con- straint that each of the digits zero through nine be used just once in the first and second half of each of the $\mathbf{5 0}$ strings.

Five conditions (Groups I-V) of input timing distributions were examined. In Group 1, 20 digits were displayed one at a time in the same location on the display, at an input rate of 2 sec. per digit, or a total of $40 \mathrm{sec}$. for the display of the entire 20 digit string. It should be noted that in Groups I-V the time spent in erasing one digit from the display and "painting on" a subsequent digit was fixed at $1 \mathrm{msec}$. In Group II, 10 digits were displayed one at a time in the same location on the display, at an input rate of $1 \mathrm{sec}$. per digit, followed by a $20 \mathrm{sec}$. period of no display, followed by the remaining 10 digits, at an input rate of $1 \mathrm{sec}$. per digit, again totalling $40 \mathrm{sec}$. for display of the entire string. In Group III, six digits (1 sec. per digit) were displayed, followed by a $10 \mathrm{sec}$. period of no display, followed by seven digits ( 1 sec. per digit), followed by $10 \mathrm{sec}$. of no display, followed by the final seven digits ( 1 sec. per digit), again with a total display time of 40 sec. In Group IV, five digits (1 sec. per digit) were displayed, followed by $6.66 \mathrm{sec}$. of no display, another five digits, $6.67 \mathrm{sec}$. of no display, another five digits, $6.67 \mathrm{sec}$. of no display, and the final five digits. In Group V, four digits ( 1 sec. per digit) were displayed, followed by $5 \mathrm{sec}$. of no display, another four digits, another $5 \mathrm{sec}$. of no display, another four digits, etc., until a total of 20 digits had been displayed.

In brief, in Groups I-V, total display time was always 40 sec., with the 20 digits evenly distributed thiough time only in Group I, while in Groups II-V, one, two, three, or four periods of no display were introduced, between various segments of the 20 digit string. Ten different strings were used for each of the five groups, with all Ss receiving the 50 strings in the same order proceeding from Group I through Group V. Immediately after the presentation of each of the 50 strings $S$ was required to recall in their correct order the 20 digits just presented to him.

\section{Results and Discussion}

For Groups $\mathrm{I}-\mathrm{V}$, the mean number of digits correctly recalled (C) was calculated; also calculated were the mean number of digits that were misplaced (M) or omitted (O). These results are as follows: Group I: $\mathrm{C}-6.5, \mathrm{M}-4.5, \mathrm{O}-9.0$; Group II: $\mathrm{C}-7.5, \mathrm{M}-4.5, \mathrm{O}-8.0$; Group III: C-8.7, M-3.6, O-7.7; Group IV: C-9.2, M-3.4, O-7.4; Group V: C-9.6, M-3.0, O-7.4. An application of the Friedman two-way analysis of variance by ranks test (Siegel, 1956, pp. 166-172) to the scores associated 
with the five means for correct recall in Groups I-V (i.e., 6.5, 7.5, 8.7,9.2, and 9.6, respectively) yielded a $x^{2}=44(p<.001)$, and clearly shows a highly significant and systematic increase in mean correct recall from Group I to Group V.

Of greater interest, perhaps, than the mean number of digits correctly recalled in the five groups, are the serial position curves for Groups I-V. These curves arc shown in Fig. 1, with the light vertical lines in Groups II-V ocuarring at those timing intervals in the display sequence when no digits were displayed. These results show very clearly that in Group I with the 20 digits distributed evenly over the $40 \mathrm{sec}$. display period the classic single-bowed serial position curve is obtained. However, in Groups II-V, the curves reveal multi-bowed shapes in direct correspondence with the input timing distributions that were examined.

This multi-bowed effect has been observed before in a study by Wishner, Shipley, \& Hurvich (1957). However, in the Wishner study the method employed was the standard serial anticipation task using nonsensesyllables and with a criterion of learning of one perfect recitation. Further, $\mathrm{S}$ was told the experiment involved

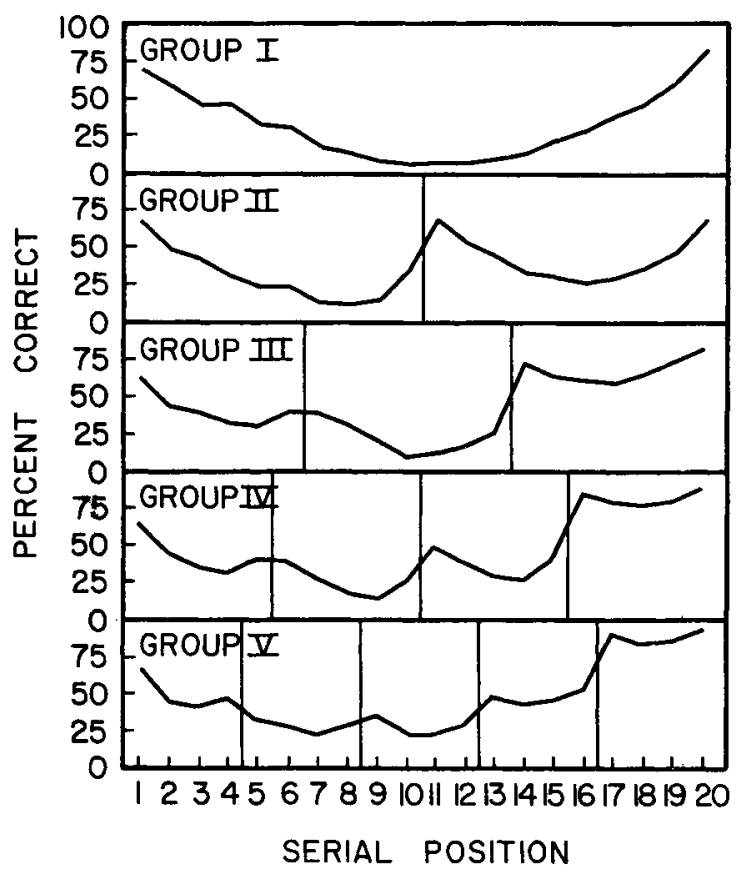

Fig. 1. Serial position curves for Groups I-V. discovering how people learn two or three list: simnltaneously when the lists differ in color or style of type, with in one condition a 14-item list composed of seven nonsense syllables typed in black caps and the second seven syllables typed in red lower-case letters being employed, and in a second condition an 18-item list composed of six green syllables, sixblack syllables, and six red syllables being employed.

In the present study, in contrast, item distribution through time was the critical variable being investigated and $S$ was not explicitly instructed to deal with the various segments of the total 20 digit string as separate components or lists. However, the highly systematic multi-bowing effect that was found strongly suggests that input "chunking" is highly time-locked to or time dependent on the input timing distribution being employed. In addition, certain input timing distributions can yield marked increases in the total amount of information stored and subsequently retrieved (i.e., Group I with 6.5 digits correctly recalled versus Group V with 9.6 digits correctly recalled). Further extensive investigation will be required to determine precisely those input timing distributions which will maximize recall for various combinations of string lengths and total display times. Also, the multi-bowing effects found in the present study pose a variety of theoretical problems. For example, are the periods during which no digits are displayed employed by Ss to implicitly rehearse the just previously presented sequence, thus leading to a consolidation of the traces associated with these sequences, and so yielding several somewhat separate serial position curves and also concomitant increases in the total amount recalled, or is a more complicated mechanism involved?

\section{References}

Mayzner, M. S., \& Adler, S. A further study of information “chunking" and short-term retention. J. Psychol., 1965, 59, 125-130.

Mayzner, M. S., \& Gabriel, R. F. Information “chunking” and short-term retention, J. Psychol., 1963, 56, 161-164.

Miller, G. A. The magical number seven, plus or minus two: Some limits on our capacity for processing information. Psychol. Rev., $1956,63,81-97$.

Siegel, $\mathbf{S}$. Nonparametric statistics for the behavioral sciences. New York: McGraw-Hill, 1956.

Wishner, J., Shipley, T. E., Jr., \& Hurvich, M. S. The serial-position curve as a function of organization. Amer. J. Psychol., $1957,70,258-262$.

\section{Nofe}

1. This research was supported in part by Contract Nonr 285(56) between the Engineering Psychology Branch of the Office of Naval Research and New York University. 